\title{
Association Studies of the GPR103 and BCL2L15 Genes in Autoimmune Thyroid Disease in the Japanese Population
}

\author{
Yoshiyuki Ban ${ }^{1 *}$, Teruaki Tozaki ${ }^{2}$ and Yasuko Nakano ${ }^{2}$ \\ ${ }^{1}$ Third Department of Internal Medicine, Teikyo University Chiba Medical Center, Ichihara, Chiba, Japan, ${ }^{2}$ Department of \\ Pharmacogenomics, Showa University School of Pharmacy, Tokyo, Japan
}

OPEN ACCESS

Edited by: Yaron Tomer Albert Einstein College of Medicine, USA

Reviewed by:

Angela Lombardi, Icahn School of Medicine at Mount Sinai, USA Amanda Katherine Huber, University of Michigan, USA Misa Imaizumi, Radiation Effects Research

Foundation, Japan

*Correspondence: Yoshiyuki Ban yshyban@yahoo.co.jp

Specialty section: This article was submitted to Thyroid Endocrinology, a section of the journal Frontiers in Endocrinology

Received: 26 May 2016 Accepted: 01 July 2016 Published: 19 July 2016

Citation:

Ban Y, Tozaki T and Nakano Y (2016) Association Studies of the GPR103 and BCL2L15 Genes in Autoimmune Thyroid Disease in the Japanese Population.

Front. Endocrinol. 7:92. doi: 10.3389/fendo.2016.00092
While the past genome-wide association study (GWAS) for autoimmune thyroid diseases (AITDs) was done in Caucasians, a recent GWAS in Caucasian patients with both AITD and type 1 diabetes [a variant of autoimmune polyglandular syndrome type 3 (APS3v)] identified five non-HLA genes: BCL2L15, MAG/3, PHTF1, PTPN22, and GPR103. The aim of our study was to replicate these associations with AITD in a Japanese population. Since analyzing the rs2476601 single-nucleotide polymorphism (SNP) within the PTPN22 gene revealed no polymorphism in the Japanese, we analyzed four SNPs, rs2358994 (in BCL2L15), rs2153977 (in MAG/3), rs1111695 (in PHTF1), and rs7679475 (in GPR103) genotypes in a case-control study based on 447 Japanese AITD patients [277 Graves' disease (GD) and 170 Hashimoto's thyroiditis (HT) patients] and 225 matched Japanese controls using the high-resolution melting and unlabeled probe methods. Case-control association studies were performed using the $\chi^{2}$ and Fisher's exact tests with Yates correction. The $G$ allele of rs7679475 (A/G) was associated with HT compared with controls $[P=0.022$, odds ratio $(O R)=0.69]$. GD showed no significant associations with any SNPs. However, when patients with GD were stratified according to Graves' ophthalmopathy (GO), the $G$ allele of $r s 2358994$ (A/G) was associated with $G O$ vs. controls $(P=0.018, \mathrm{OR}=1.52)$. These findings suggest that in the Japanese population the GPR103 gene may contribute to the pathogenesis of HT. Moreover, this study demonstrated that the SNP rs2358994 within BCL2L15 gene is associated with GO in the Japanese population.

Keywords: Graves' disease, Hashimoto's thyroiditis, genetics, autoimmunity, association

\section{INTRODUCTION}

Autoimmune thyroid diseases (AITDs), including Graves' disease (GD) and Hashimoto's thyroiditis (HT), are among the most common human autoimmune diseases. The prevalence in Caucasians is $1 \%(1,2)$, and the prevalence in Japanese is not known. GD is characterized clinically by hyperthyroidism, diffuse goiter, and the presence of thyrotropin receptor (TSHR) antibodies. Some patients develop extrathyroidal manifestations, mainly ophthalmopathy and dermopathy [reviewed by Davies (3)]. Stimulatory TSHR autoantibodies are directly responsible for hyperthyroidism in GD. However, despite their contrasting clinical presentations, GD and HT share many common features, including the presence of autoantibodies to thyroid peroxidase and/or thyroglobulin, but rarely to the TSHR (3-5). 
The pathogenesis of AITDs is thought to involve several risk factors, including genetic risk factors [reviewed in Ref. (6)] and environmental triggers, such as cigarette smoking, iodine intake, and infection $(7,8)$ [reviewed by Davies (3)]. However, the evidence for interactions between hereditary factors and environmental influences appears to be much stronger for cigarette smoking and iodine intake than for infections (8).

While the past genome-wide association study (GWAS) for AITDs was done in Caucasians, Lombardi et al. identified three new single-nucleotide polymorphisms (SNPs) on chromosome $3 \mathrm{q}$ that are associated with GD in Italian patients indicating potential GD susceptibility genes in this locus (9). Recently, Immunochip genetic association analysis identified 30 SNPs in several genes that were significantly associated with YoungAge-of-Onset GD, including major histocompatibility complex class I and class II genes, BTNL2, NOTCH4, TNFAIP3, and CXCR4 (10).

Moreover, the first GWAS performed in patients that developed both type 1 diabetes (T1D) and AITD [a variant of autoimmune polyglandular syndrome type 3 (APS3v)] was reported (11). Indeed, the co-occurrence of T1D and AITD in the same individual is classified as a variant of the autoimmune APS3v. They identified multiple signals within the HLA region, and conditioning studies suggested that a few of them contributed independently to the strong association of the HLA locus with APS3v (11). Outside the HLA region, variants in G protein-coupled receptor 103 (GPR103) located on chromosome 4q27, a gene not suggested by previous studies of APS3v, T1D, or AITD, showed genome-wide significance $\left(P<5 \times 10^{-8}\right)(11)$. Moreover, a locus on 1 p13 containing four genes [B-cell lymphoma 2-like protein 5 (BCL2L15), membrane-associated guanylate kinase, WW and PDZ domaincontaining 3 (MAGI3), putative homeodomain transcription factor 1 (PHTF1), and protein tyrosine phosphatase nonreceptor type 22 (PTPN22)] showed genome-wide significant associations (11). Because of possible genetic heterogeneity between different ethnic groups, we aimed to replicate in the Japanese population the associations between AITD and the four SNPs, rs2358994 (in BCL2L15), rs2153977 (in MAGI3), rs1111695 (in PHTF1), and rs7679475 (in GPR103), recently reported in Caucasians. Types of all these SNPs we studied are nonsense. Since analyzing the rs2476601 SNP within the PTPN22 gene revealed no polymorphism in the Japanese, we did not analyze it in the present study.

\section{MATERIALS AND METHODS}

\section{Ethics Statement}

The research protocol was approved by the Ethic Committee and each subject signed the informed consent form approved by the Institutional Review Board.

\section{Patients and Controls AITD Patients}

Four hundred forty-seven unrelated Japanese AITD patients (age range, 30-80 years) were studied. There were a total of 277 GD patients (69 males and 208 females) and $170 \mathrm{HT}$ patients
(17 males and 153 females). Of the 277 GD patients, 89 (32.1\%) had Graves' ophthalmopathy (GO).

\section{Clinical Assessment}

Graves' disease was diagnosed based on clinical symptoms and biochemical confirmation of hyperthyroidism, including diffuse goiter, elevated radioactive iodine uptake, and elevated thyroid hormone levels. Ophthalmopathy was classified according to the system recommended by the American Thyroid Association (ATA) Committee (12). Eighty-nine of the GD patients showed ophthalmopathy defined as ATA class III or greater and were classified as GO. HT patients had documented clinical and biochemical hypothyroidism requiring thyroid hormone replacement therapy and showed autoantibodies against thyroid peroxidase with or without antibodies against thyroglobulin.

\section{Controls}

Two hundred twenty-five age- and sex-matched healthy Japanese volunteers (79 males and 146 females; age range, 34-72 years) served as controls in our association studies. All controls had no personal or family history of any autoimmune disease.

\section{SNP Typing}

DNA was extracted from whole blood using the Puregene kit (Gentra Systems, Minneapolis, MN, USA). Four SNPs (rs2358994, rs2153977, rs1111695, and rs7679475) were genotyped by the high-resolution melting and unlabeled probe methods using LightScanner (Idaho Technology Inc., Salt Lake City, UT, USA) based on the manufacture's protocol.

\section{Statistical Analysis}

Case-control analysis and Hardy-Weinberg equilibrium (HWE) test of SNP were performed using SNPALyze ver. 7.0 (Dynacom, Yokohama, Japan) (13). Differences in the allele frequencies between the groups were analyzed using the chi-square test for two by two and two by three and Fisher's exact test with Yates correction. The odds ratio (OR) was calculated using the modified method of Woolf (14). A $P$-value of $<0.05$ was considered statistically significant. HWE tests were carried out for all loci among subjects and controls separately.

\section{RESULTS}

Tests in subjects and controls did not show any significant deviation from HWE for any of the SNPs (data not shown). Analyzing the rs2476601 SNP within the PTPN22 gene revealed no polymorphism in the Japanese (15). Table 1 shows the allele and genotype frequencies of four SNPs at the two risk loci (1p13 and 4q27) in AITD patients and controls. SNP rs7679475 (A/G) within the GPR103 gene showed significant association with HT. The $\mathrm{G}$ allele of rs7679475 was present in $22.9 \%$ of HT patients and $30.2 \%$ of controls $[P=0.023, \mathrm{OR}=0.69,95 \%$ confidence interval (CI): 0.4976-0.9495], and the distribution of genotype frequencies differed significantly between HT patients and controls $(P=0.046)$. There were no significant associations between HT and other three SNPs. GD showed no significant associations with any SNPs. 
TABLE 1 | Case-control association results for the four SNPs at the two risk loci (1p13 and 4q27).

\begin{tabular}{|c|c|c|c|c|c|c|c|c|c|c|}
\hline SNP & CHR & Gene & $\begin{array}{l}\text { Allele/ } \\
\text { genotype }\end{array}$ & $\begin{array}{c}\text { Control } \\
(n=225)\end{array}$ & $\begin{array}{c}\text { AITD } \\
(n=447)\end{array}$ & $\begin{array}{c}P \text { value }^{\mathrm{a}}(\mathrm{OR}) \\
\text { AITD vs. control }\end{array}$ & $\begin{array}{c}\text { GD } \\
(n=277)\end{array}$ & $\begin{array}{l}P \text { value }^{\mathrm{a}}(\mathrm{OR}) \\
\text { GD vs. control }\end{array}$ & $\begin{array}{c}\text { HT } \\
(n=170)\end{array}$ & $\begin{array}{l}P \text { value }{ }^{\text {a }}(\mathrm{OR}) \\
\text { HT vs. contro }\end{array}$ \\
\hline \multirow[t]{5}{*}{ rs2358994 } & $1 \mathrm{p} 13$ & BCL2L15 & $A$ & $257(57.1)$ & 481 (53.8) & & 301 (54.3) & & 180 (52.9) & \\
\hline & & & $G$ & 193 (42.9) & $413(46.2)$ & 0.25 & $253(45.7)$ & 0.38 & $160(47.1)$ & 0.24 \\
\hline & & & $\mathrm{A} / \mathrm{A}$ & 73 (32.4) & $130(29.1)$ & & 84 (30.3) & & $46(27.1)$ & \\
\hline & & & $A / G$ & 111 (49.3) & 221 (49.4) & & $131(48.0)$ & & 88 (51.8) & \\
\hline & & & $\mathrm{G} / \mathrm{G}$ & 41 (18.2) & 96 (21.5) & 0.51 & $60(21.7)$ & 0.62 & $36(21.2)$ & 0.48 \\
\hline \multirow[t]{5}{*}{ rs2153977 } & $1 p 13$ & MAGI3 & $\mathrm{T}$ & 269 (59.8) & 506 (56.6) & & $319(57.6)$ & & 187 (55.0) & \\
\hline & & & C & 181 (40.2) & $388(43.4)$ & 0.27 & $235(42.4)$ & 0.48 & $153(45.0)$ & 0.18 \\
\hline & & & $\mathrm{T} / \mathrm{T}$ & 84 (37.3) & 144 (32.2) & & 94 (33.9) & & 50 (29.4) & \\
\hline & & & $\mathrm{T} / \mathrm{C}$ & 101 (44.9) & $218(48.8)$ & & $131(47.3)$ & & 87 (51.2) & \\
\hline & & & $\mathrm{C} / \mathrm{C}$ & 40 (17.8) & 85 (19.0) & 0.42 & 52 (18.8) & 0.73 & $33(19.4)$ & 0.25 \\
\hline \multirow[t]{5}{*}{ rs1111695 } & $1 \mathrm{p} 13$ & PHTF1 & $\mathrm{T}$ & $83(18.4)$ & 186 (20.8) & & 114 (20.6) & & $72(21.2)$ & \\
\hline & & & $\mathrm{G}$ & 367 (81.6) & 708 (79.2) & 0.31 & $440(79.4)$ & 0.40 & $268(78.8)$ & 0.34 \\
\hline & & & $\mathrm{T} / \mathrm{T}$ & $12(5.3)$ & $27(6.0)$ & & $17(6.1)$ & & $10(5.9)$ & \\
\hline & & & $\mathrm{T} / \mathrm{G}$ & $59(26.2)$ & 132 (29.5) & & 80 (28.9) & & 52 (30.6) & \\
\hline & & & $\mathrm{G} / \mathrm{G}$ & $154(68.4)$ & $288(64.4)$ & 0.59 & $180(65.0)$ & 0.72 & 108 (63.5) & 0.59 \\
\hline \multirow[t]{5}{*}{ rs7679475 } & $4 q 27$ & GPR103 & A & 314 (69.8) & 660 (73.8) & & 398 (71.8) & & $262(77.1)$ & \\
\hline & & & $\mathrm{G}$ & 136 (30.2) & 234 (26.2) & 0.12 & $156(28.2)$ & 0.47 & 78 (22.9) & $0.023(0.69)^{b}$ \\
\hline & & & $\mathrm{A} / \mathrm{A}$ & 109 (48.4) & $242(54.1)$ & & $144(52.0)$ & & 98 (57.6) & \\
\hline & & & $A / G$ & $96(42.7)$ & 176 (39.4) & & $110(39.7)$ & & 66 (38.8) & \\
\hline & & & $\mathrm{G} / \mathrm{G}$ & $20(8.9)$ & $29(6.5)$ & 0.28 & 23 (8.3) & 0.73 & $6(3.5)$ & $0.046^{c}$ \\
\hline
\end{tabular}

Values given are the number of subjects, with the percentage in parentheses.

SNP, single-nucleotide polymorphism; CHR, chromosome; OR, odds ratio.

a $P$-value based on $\chi^{2}$ distribution.

${ }^{b}$ The distribution of allele frequencies differed significantly between HT patients and controls.

'The distribution of genotype frequencies differed significantly between HT patients and controls.

Since cell-mediated immunity plays a central role in the pathogenesis of GO, similar to Crohn's disease and rheumatoid arthritis (16), we tested the four SNPs for association with the subset of our GD patients that had GO (Table 2). SNP rs2358994 $(\mathrm{A} / \mathrm{G})$ within the B-cell lymphoma 2-like protein 15 (BCL2L15) gene was associated with GO compared with controls $(P=0.018$, $\mathrm{OR}=1.52,95 \% \mathrm{CI}: 1.08-2.16)$ and GD without GO $(P=0.012$, $\mathrm{OR}=1.58,95 \%$ CI: $1.10-2.27$ ) (Table 2). The G allele of rs2358994 was present in $53.4 \%$ of GO patients and $42.9 \%$ of controls ( $P=0.018$, OR $=1.52,95 \% \mathrm{CI}: 1.08-2.16)$, and the distribution of genotype frequencies differed significantly between $\mathrm{GO}$ patients and controls $(P=0.033)$. There were no significant associations between GO and other three SNPs. These data suggested that the BCL2L15 gene may be associated with GO.

\section{DISCUSSION}

In this study, we replicated the association of the $G$ allele of the rs7679475(A/G) SNP within the GPR103 gene with HT in Japanese population. It should be noted that a locus on chromosome 4q27 that is approximately $625 \mathrm{kB}$ downstream the GPR103 gene was previously reported to be associated with T1D (17), as well as with other autoimmune diseases, including rheumatoid arthritis (18), Celiac disease (19), and ulcerative colitis (20). However, there was no association between rs7679475 and GD. Tomer et al. (11) previously tested the two GPR103 SNPs (rs1513695, and rs7679475) showing association with APS3v, for association with AITD in their AITD dataset. The analysis showed that the two SNPs were both associated with HT, but not with GD (11). Our data and the data of Tomer et al. suggested that the GPR103 gene may contribute to the pathogenesis of HT in Caucasian and Japanese patients. The GPR103 gene (also designated as QRFPR gene) is a G-protein-coupled receptor that is expressed not only in brain but also in human pancreatic islets, and it may have an effect on insulin secretion (21). The ligand for GPR103 (P518) is expressed in thyroid cells (22). Therefore, the mechanism by which the GPR103 gene may predispose to thyroid autoimmunity is still unclear.

The frequency of the $G$ allele of the rs2358994 (A/G) was also found to be associated with GO in Japanese. The GWAS in patients with APS3v (11) mapped four genes (BCL2L15, MAGI3, PHTF1, and PTPN22) that are located in the same locus on chromosome $1 \mathrm{p} 13$ and are in linkage disequilibrium (LD) (11). Since the rs2476601 SNP within the PTPN22 gene revealed no polymorphism in the Japanese (15), we tested three additional SNPs in this locus (rs2358994, rs2153977, and rs1111695) for association with AITD. Although both GD and HT showed no significant associations with any of these SNPs, there was a significant association between GO and rs2358994, suggesting that the BCL2L15 gene may be a GO-specific gene in Japanese. SNP rs2358994 showed significant association only with GO, but not with GD without GO. This SNP is located within the BCL2L15 gene, which is in tight LD with PTPN22 (11). Therefore, at present, we cannot determine if this association reflects an association with the BCL2L15 gene, PTPN22 gene, or another gene within this locus, and further studies are needed to determine that.

The BCL2L15 gene (also designated as BFK gene) is a proapoptotic member of the BCL2 family $(23,24)$. Reduction in BCL2L15 protein expression is observed in gastrointestinal tumors (25). 
TABLE 2 | Frequencies of alleles and genotypes of the four SNPs in Graves' patients with and without ophthalmopathy (GO).

\begin{tabular}{|c|c|c|c|c|c|c|c|c|}
\hline SNP & $\begin{array}{l}\text { Allele/ } \\
\text { genotype }\end{array}$ & $\begin{array}{c}\text { Control } \\
(n=225)\end{array}$ & $\begin{array}{c}\text { GD } \\
(n=277)\end{array}$ & $\begin{array}{c}\text { GO } \\
(n=89)\end{array}$ & $\begin{array}{l}\text { GD without } \\
\text { GO (n=188) }\end{array}$ & $\begin{array}{l}P \text { value }^{\mathrm{a}} \\
\text { (OR) GO vs. } \\
\text { control }\end{array}$ & $\begin{array}{l}P \text { value }{ }^{\text {a }}(O R) \\
\text { GO vs. GD } \\
\text { without GO }\end{array}$ & $\begin{array}{l}P \text { value }(\text { OR) } \\
\text { GD without } \\
\text { GO vs. control }\end{array}$ \\
\hline \multirow[t]{5}{*}{ rs2358994 } & $A$ & $257(57.1)$ & 301 (54.3) & 83 (46.6) & 218 (58.0) & & & \\
\hline & $\mathrm{G}$ & 193 (42.9) & $253(45.7)$ & $95(53.4)$ & $158(42.0)$ & $0.018(1.52)^{b}$ & $0.012(1.58)^{d}$ & 0.80 \\
\hline & AVA & 73 (32.4) & 84 (30.3) & $16(18.0)$ & 68 (36.2) & & & \\
\hline & $A / G$ & 111 (49.3) & 133 (48.0) & 51 (57.3) & $82(43.6)$ & & & \\
\hline & $\mathrm{G} / \mathrm{G}$ & $41(18.2)$ & $60(21.7)$ & $22(24.7)$ & 38 (20.2) & $0.033^{c}$ & $0.0086^{e}$ & 0.51 \\
\hline \multirow[t]{5}{*}{ rs2153977 } & $\mathrm{T}$ & 269 (59.8) & 319 (57.6) & $94(52.8)$ & 225 (59.8) & & & \\
\hline & C & 181 (40.2) & 235 (42.4) & $84(47.2)$ & $151(40.2)$ & 0.11 & 0.12 & 0.99 \\
\hline & $\mathrm{T} / \mathrm{T}$ & 84 (37.3) & 94 (33.9) & $28(31.5)$ & $66(35.1)$ & & & \\
\hline & $\mathrm{T} / \mathrm{C}$ & 101 (44.9) & $131(47.3)$ & $38(42.7)$ & 93 (49.5) & & & \\
\hline & $\mathrm{C} / \mathrm{C}$ & $40(17.8)$ & $52(18.8)$ & $23(25.8)$ & $29(15.4)$ & 0.25 & 0.12 & 0.63 \\
\hline \multirow[t]{5}{*}{ rs1111695 } & $\mathrm{T}$ & 83 (18.4) & $114(20.6)$ & 38 (21.3) & $76(20.2)$ & & & \\
\hline & $\mathrm{G}$ & 367 (81.6) & $440(79.4)$ & $140(78.7)$ & $300(79.8)$ & 0.41 & 0.76 & 0.52 \\
\hline & $\mathrm{T} / \mathrm{T}$ & 12 (5.3) & $17(6.1)$ & $8(9.0)$ & $9(4.8)$ & & & \\
\hline & $\mathrm{T} / \mathrm{G}$ & $59(26.2)$ & 80 (28.9) & $22(24.7)$ & 58 (30.9) & & & \\
\hline & $\mathrm{G} / \mathrm{G}$ & $154(68.4)$ & $180(65.0)$ & 59 (66.3) & $121(64.4)$ & 0.49 & 0.28 & 0.58 \\
\hline \multirow[t]{5}{*}{ rs7679475 } & $A$ & 314 (69.8) & 398 (71.8) & 122 (68.5) & 276 (73.4) & & & \\
\hline & $G$ & 136 (30.2) & $156(28.2)$ & $56(31.5)$ & $100(26.6)$ & 0.76 & 0.23 & 0.25 \\
\hline & AVA & 109 (48.4) & $144(52.0)$ & $42(47.2)$ & 102 (54.3) & & & \\
\hline & $A / G$ & $96(42.7)$ & $110(39.7)$ & $38(42.7)$ & 72 (38.3) & & & \\
\hline & $\mathrm{G} / \mathrm{G}$ & 20 (8.9) & $23(8.3)$ & $9(10.1)$ & $14(7.4)$ & 0.94 & 0.50 & 0.49 \\
\hline
\end{tabular}

Values given are the number of subjects, with the percentage in parentheses.

SNP, single nucleotide polymorphism; OR, odds ratio.

a $P$-value based on $\chi^{2}$ distribution.

${ }^{b}$ The distribution of allele frequencies differed significantly between GO patients and controls.

cThe distribution of genotype frequencies differed significantly between GO patients and controls.

${ }^{d}$ The distribution of allele frequencies differed significantly between GD with and without GO patients.

eThe distribution of genotype frequencies differed significantly between GD with and without GO patients.

Interestingly, higher levels of the BCL2 protein was registered in freshly isolated Crohn's disease patient polymorphonuclear neutrophils, in contrast to controls, in which BCL2 protein was undetectable (26). These data suggest that the defective functionality of neutrophils can be the early event responsible for the altered mucosal immune response in Crohn's disease, which is one of the autoimmune diseases.

There are two limitations of the present study. First, the number of samples is relatively small that may have limited our ability to identify common variants with weak effects. Second, controls selection process may be insufficient. However, all the controls have been screened for T3/T4 of other thyroid-related phenotypes. Also, all study participants lived in the Tokyo metropolitan area. Moreover, quality control (QC) testing, including testing for HWE, was performed using SNPALyze ver. 7.0 (http://www. dynacom.co.jp/e/products/package/snpalyze/). Tests in subjects and controls did not show any significant deviation from HWE for any of the SNPs.

In conclusion, we replicated an association between HT and the $\mathrm{G}$ allele of rs7679475 within the GPR103 gene in Japanese.

\section{REFERENCES}

1. Jacobson DL, Gange SJ, Rose NR, Graham NM. Epidemiology and estimated population burden of selected autoimmune diseases in the United States. Clin Immunol Immunopathol (1997) 84:223-43. doi:10.1006/clin.1997.4412

2. Hollowell JG, Staehling NW, Flanders WD, Hannon WH, Gunter EW, Spencer CA, et al. Serum TSH, T(4), and thyroid antibodies in the United States population (1988 to 1994): National Health and Nutrition Examination Survey
These results suggest the GPR103 gene may contribute to the pathogenesis of HT in both Caucasians and Japanese. We also, for the first time, identified the association of SNP rs2358994 within BCL2L15 gene with GO in the Japanese population, suggesting genetic influences in different ethnic populations (27). Studies with ethnically diverse populations, including large numbers of patients, are needed to confirm the role of above two genes in AITD.

\section{AUTHOR CONTRIBUTIONS}

YB and TT: conceived, designed, and performed the experiments, analyzed the data, and contributed reagents/materials/analysis tools; YB, TT, and YN: wrote the paper.

\section{FUNDING}

This work was supported in part by a Grant-in-Aid for Scientific Research (25461365) from the Ministry of Education, Science, Sports, Culture, and Technology, Japan (to YB).

(NHANES III). J Clin Endocrinol Metab (2002) 87:489-99. doi:10.1210/ jcem.87.2.8182

3. Davies TF. Graves' diseases: pathogenesis. In: Braverman LE, Utiger RD, editors. Werner and Ingbar's The Thyroid: A Fundamental and Clinical Text. Philadelphia: Lippincott-Raven (2000). p. 518-30.

4. Weetman AP. Chronic autoimmune thyroiditis. In: Braverman LE, Utiger RD, editors. Werner and Ingbar's The Thyroid: A Fundamental and Clinical Text. Philadelphia: Lippincott-Raven (1996). p. 738-48. 
5. Tomer Y. Anti-thyroglobulin autoantibodies in autoimmune thyroid diseases: cross-reactive or pathogenic? Clin Immunol Immunopathol (1997) 82:3-11. doi:10.1006/clin.1996.4243

6. Tomer Y, Davies TF. Searching for the autoimmune thyroid disease susceptibility genes: from gene mapping to gene function. Endocr Rev (2003) 24:694-717. doi:10.1210/er.2002-0030

7. Tomer Y, Davies TF. Infection, thyroid disease and autoimmunity. Endocr Rev (1993) 14:107-20. doi:10.1210/er.14.1.107

8. Brix TH, Hansen PS, Kyvik KO, Hegedus L. Cigarette smoking and risk of clinically overt thyroid disease: a population-based twin case-control study. Arch Intern Med (2000) 160:661-6. doi:10.1001/archinte.160.5.661

9. Lombardi A, Menconi F, Greenberg D, Concepcion E, Leo M, Rocchi R, et al. Dissecting the genetic susceptibility to Graves' disease in a cohort of patients of Italian origin. Dissecting the genetic susceptibility to Graves' disease in a cohort of patients of Italian origin. Front Endocrinol (2016) 7:21. doi:10.3389/ fendo.2016.00021

10. Brown RS, Lombardi A, Hasham A, Greenberg DA, Gordon J, Concepcion E, et al. Genetic analysis in young-age-of-onset Graves' disease reveals new susceptibility loci. J Clin Endocrinol Metab (2014) 99:E1387-91. doi:10.1210/ jc.2013-4358

11. Tomer Y, Dolan LM, Kahaly G, Divers J, D’Agostino RB Jr, Imperatore G, et al. Genome wide identification of new genes and pathways in patients with both autoimmune thyroiditis and type 1 diabetes. J Autoimmun (2015) 60:32-9. doi:10.1016/j.jaut.2015.03.006

12. Werner SC. Modification of the classification of the eye changes of Graves' disease: recommendation of the ad hoc committee of the American Thyroid Association. J Clin Endocrinol Metab (1977) 44:203-4. doi:10.1210/ jcem-44-1-203

13. Dynacom Website (2014). Available from: http://www.dynacom.co.jp/e/ products/package/snpalyze/

14. Woolf B. On estimating the relation between blood group and disease. Ann Hum Genet (1955) 19:251-3. doi:10.1111/j.1469-1809.1955.tb01348.x

15. Ban Y, Tozaki T, Taniyama M, Tomita M, Ban Y. The codon 620 single nucleotide polymorphism of the protein tyrosine phosphatase-22 gene does not contribute to autoimmune thyroid disease susceptibility in the Japanese. Thyroid (2005) 15:1115-8. doi:10.1089/thy.2005.15.1115

16. Bahn R. Pathophysiology of Graves' ophthalmopathy: the cycle of disease. J Clin Endocrinol Metab (2003) 88:1939-46. doi:10.1210/jc.2002-030010

17. Barrett JC, Clayton DG, Concannon P, Akolkar B, Cooper JD, Erlich HA, et al. Genome-wide association study and meta-analysis find that over 40 loci affect risk of type 1 diabetes. Nat Genet (2009) 41:703-7. doi:10.1038/ ng.381

18. Stahl EA, Raychaudhuri S, Remmers EF, Xie G, Eyre S, Thomson BP, et al. Genome-wide association study meta-analysis identifies seven new rheumatoid arthritis risk loci. Nat Genet (2010) 42:508-14. doi:10.1038/ng.582
19. van Heel DA, Franke L, Hunt KA, Gwilliam R, Zhernakova A, Inouye M, et al. A genome-wide association study for celiac disease identifies risk variants in the region harboring IL2 and IL21. Nat Genet (2007) 39:827-9. doi:10.1038/ ng2058

20. Anderson CA, Boucher G, Lees CW, Franke A, D’Amato M, Taylor KD, et al. Meta-analysis identifies 29 additional ulcerative colitis risk loci, increasing the number of confirmed associations to 47. Nat Genet (2011) 43:246-52. doi:10.1038/ng.764

21. Granata R, Settanni F, Trovato L, Gallo D, Gesmundo I, Nano R, et al. RFamide peptides $43 \mathrm{RFa}$ and $26 \mathrm{RFa}$ both promote survival of pancreatic $\beta$-cells and human pancreatic islets but exert opposite effects on insulin secretion. Diabetes (2014) 63:2380-93. doi:10.2337/db13-1522

22. Jiang Y, Luo L, Gustafson EL, Yadav D, Laverty M, Murgolo N, et al. Identification and characterization of a novel RF-amide peptide ligand for orphan G-protein-coupled receptor SP9155. J Biol Chem (2003) 278:27652-7. doi:10.1074/jbc.M302945200

23. Coultas L, Pellegrini M, Visvader JE, Lindeman GJ, Chen L, Adams JM, et al. Bfk: a novel weakly proapoptotic member of the Bcl-2 protein family with a BH3 and a BH2 region. Cell Death Differ (2003) 10:185-92. doi:10.1038/ sj.cdd. 4401204

24. Pujianto DA, Damdimopoulos AE, Sipilä P, Jalkanen J, Huhtaniemi I, Poutanen M. Bfk, a novel member of the bcl2 gene family, is highly expressed in principal cells of the mouse epididymis and demonstrates a predominant nuclear localization. Endocrinology (2007) 148:3196-204. doi:10.1210/ en.2007-0018

25. Dempsey CE, Dive C, Fletcher DJ, Barnes FA, Lobo A, Bingle CD, et al. Expression of pro-apoptotic Bfk isoforms reduces during malignant transformation in the human gastrointestinal tract. FEBS Lett (2005) 579:3646-50. doi:10.1016/j.febslet.2005.05.050

26. Catarzi S, Marcucci T, Papucci L, Favilli F, Donnini M, Tonelli F, et al. Apoptosis and $\mathrm{Bax}, \mathrm{Bcl}-2, \mathrm{Mcl}-1$ expression in neutrophils of Crohn's disease patients. Inflamm Bowel Dis (2008) 14:819-25. doi:10.1002/ibd.20397

27. Ban Y. Genetics of autoimmune thyroid diseases in Asians. J Autoimmun Res (2015) 2:1006.

Conflict of Interest Statement: The authors declare that the research was conducted in the absence of any commercial or financial relationships that could be construed as a potential conflict of interest.

Copyright (C) 2016 Ban, Tozaki and Nakano. This is an open-access article distributed under the terms of the Creative Commons Attribution License (CC BY). The use, distribution or reproduction in other forums is permitted, provided the original author(s) or licensor are credited and that the original publication in this journal is cited, in accordance with accepted academic practice. No use, distribution or reproduction is permitted which does not comply with these terms. 